\title{
Three interrelated themes in current breast cancer research: gene addiction, phenotypic plasticity, and cancer stem cells
}

\author{
Robert D Cardiff**, Suzana Couto² and Brad Bolon³
}

\begin{abstract}
Recent efforts to understand breast cancer biology involve three interrelated themes that are founded on a combination of clinical and experimental observations. The central concept is gene addiction. The clinical dilemma is the escape from gene addiction, which is mediated, in part, by phenotypic plasticity as exemplified by epithelial-to-mesenchymal transition and mesenchymal-to-epithelial transition. Finally, cancer stem cells are now recognized as the basis for minimal residual disease and malignant progression over time. These themes cooperate in breast cancer, as induction of epithelial-to-mesenchymal transition enhances self-renewal and expression of cancer stem cells, which are believed to facilitate tumor resistance.
\end{abstract}

\section{Introduction}

Modern biomedical science is embodied in the principle of One Health, or the recognition that exploration of evolutionarily conserved genes and proteins in vivo and in vitro using animal models and cell lines, respectively, is a viable and robust means of understanding human health and disease [1]. The One Medicine concept was first articulated by the German physician Virchow in the 1860s [2]. Experimental cancer research is founded on fundamental discoveries made using primary and transplanted mouse breast cancer models [3]. To this armamentarium, modern investigators have added cultured and xenografted human cell lines. While critical for discerning fundamental cancer mechanisms, model systems present both opportunities and challenges for translational medicine practitioners. These opposing prospects are exemplified in three primary themes within the

*Correspondence: rdcardiff@ucdavis.edu

'Department of Pathology, Center for Comparative Medicine, University of California, Davis, County Road 98 and Hutchison Drive, Davis, CA 95616, USA Full list of author information is available at the end of the article current breast cancer literature, which are briefly reviewed and integrated here: gene addiction; phenotypic plasticity, exemplified by epithelial-to-mesenchymal transition (EMT); and cancer stem cells (CSC). In particular, the EMT phenomenon illustrates the interactions among these three themes.

\section{Historical context}

Most of the fundamental concepts underpinning gene addiction, phenotypic plasticity, CSC, and EMT are deeply embedded in the history of breast cancer research. As with many scientific questions, early investigations into these concepts were obscured by inconsistent terminology and the resulting inability to link findings identified independently by numerous researchers. For example, the hypothesis that cancer originates from an embryonic stem cell was first proposed in the late 1800s by Connheim and Virchow [4]. Connheim called the cells blastema, which Virchow erroneously proposed arose from the connective tissue [4].

The recognition of cellular plasticity can primarily be credited to the modern developmental biologists who described this epithelial-to-mesenchymal transition and coined the concept of EMT [5,6]. Medical scientists have only recently embraced EMT as a clinically significant phenomenon in cancer biology. For example, descriptions of carcinosarcomas in the mouse mammary gland noted in 1906 would be called EMT tumors 100 years later [7]. Similarly, the famed Spanish morphologist Cajal observed 'pear-like cells, not attached to each other' in human breast cancer in the late 1800 s that surely now would be noted as EMT [5]. In contrast, the concept of gene addiction in breast cancer is less than a decade old. Nevertheless, integration of gene addiction with phenotypic plasticity, EMT tumorigenesis, and CSC provides the key to an integrated mechanistic understanding of current breast cancer biology.

\section{Gene addiction as the driver for cancer induction and cancer phenotypes}

The reliance of cancer cells on expression of specific genes (gene addiction) has provided important mechanistic 
insight into the phenomena of plasticity, CSC, and EMT. The concept of gene addiction was primarily based on genetically engineered mouse (GEM) experiments in which conditional transgenic overexpression of oncogenes rapidly induced tumors [8,9]. High intralesional oncogene levels were always coupled with neoplasia, while switching off the oncogene expression led to tumor regression [10,11]. Prominent examples of such addiction in mouse breast cancer models include tumors driven by MYC, ERB2 (HER2-neu), and RASGRF1 (Ras) - oncogenes that are also upregulated in a substantial fraction of human breast cancers $[12,13]$. With the recognition of key roles for other genes in modifying cancer phenotypes, cancer gene addiction has been broadened and recently divided into two categories: oncogene addiction, and non-oncogene addiction (NOA) [14]. The genes linked to NOA do not initiate cancer per se but instead play critical roles in cancer development and progression. The NOA genes encode a large variety of molecules involved in almost all critical signaling pathways. Notably, NOA genes are usually downregulated or lost in cancer, and thus fall under the broad classification of tumorsuppressor genes (TSGs).

It is important to recognize that cancer cell addiction to both oncogenes and NOA genes has a profound effect on the histomorphology of cancers [15], resulting in genotype-specific tumor phenotypes (Figure 1). For example, loss of cadherin-1 (CDH1, also termed Ecadherin), a NOA gene, is associated with human lobular breast cancer [16] and leads to an identical pattern (phenocopy) in mouse mammary gland tumors (Figure 1A,B). In mice, overexpression of the $\mathrm{Her} 2 / \mathrm{Neu}$ oncogene results in solid nodular tumors (Figure 1C) that mimic human comedo carcinoma [17], while enhanced expression of the $M y c$ oncogene leads to hyperchromasia, an increased nuclear:cytoplasmic ratio, and enlarged nucleoli (Figure 1D). These phenotypes are readily recognized by an experienced pathologist.

The NOA concept includes the loss, mutation or downregulation of TSGs, such as BRCA1, BRCA2, PTEN, TP53 ( $p 53)$, and $R B 1(R b)$ [14]. The traditional TSGs serve as gatekeepers (by preventing excess cell proliferation) or as caretakers (by repairing DNA to maintain genome integrity). More recently, a TSG class has been identified that inhibits metastasis $[18,19]$. Loss of function for many TSGs has been linked to unique morphological phenotypes for subsets of mammary gland tumors. For example, BRCA1 is associated with medullary breast carcinomas [20], Pten deletion is linked to adenomyoepithelial differentiation in murine mammary tumors (Figure 1E), TP53 mutations are associated with EMT in cancers of the breast and other organs [21], and $R b 1$ mutations induce neuroendocrine tumors in most organs, including the breast [22]. Specific molecular

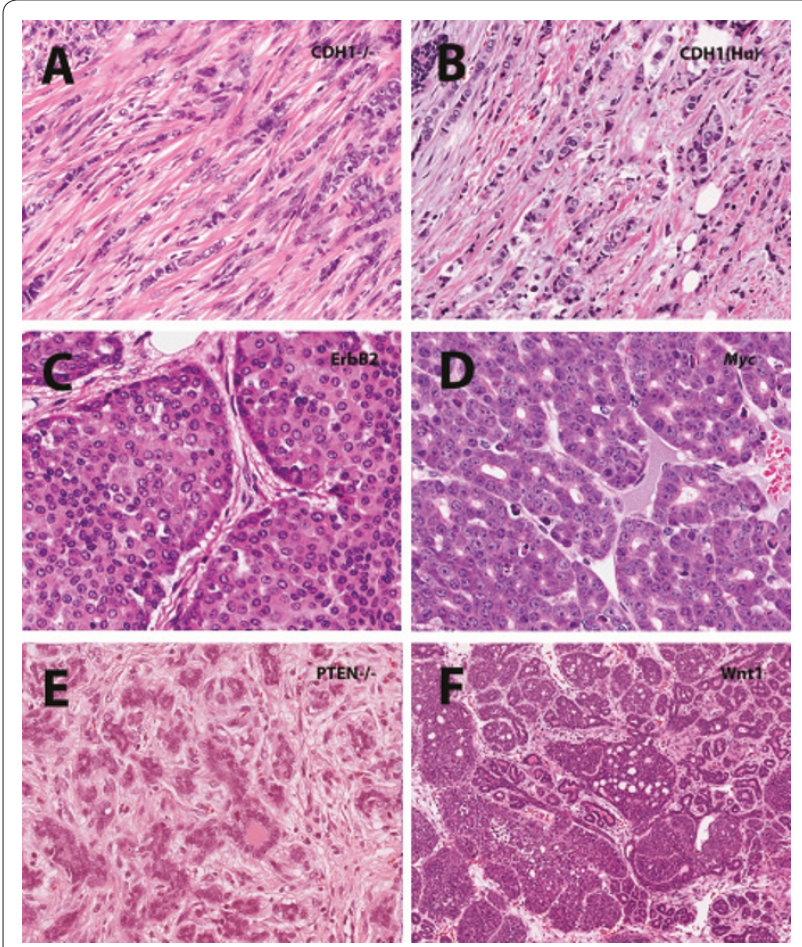

Figure 1. Breast tumor phenotypes are often associated with a specific gene addiction. (A) $\operatorname{Tm}\left(\left(\mathrm{CDH}^{-/-}\right) \times\left(\mathrm{p}^{2} 3^{-/-}\right)\right)$mice develop cadherin-1 (Cdh1)-deficient mammary tumors characterized by a single-file pattern of neoplastic epithelium infiltrating a dense stroma [43]. (B) Lobular carcinoma of the human breast is a CDH1deficient tumor that displays a similar growth pattern, with cords of neoplastic epithelium coursing through dense connective tissue. (C) $\mathrm{Tg}(\mathrm{CNeu})$ mice that overexpress the ErbB2 oncogene develop breast cancers having a solid, nodular growth pattern with relatively uniform oval nuclei and abundant red-orange cytoplasm. (D) Typical neoplastic mammary epithelial cells in Tg(cMyc) mice exhibit a high nuclear:cytoplasmic ratio along with large pleomorphic nuclei having coarse hyperchromatic chromatin and prominent nucleoli in response to overexpression of the $c-M y c$ oncogene. This tumor has a glandular pattern that is rarely seen in $\mathrm{Tg}(\mathrm{CNeu})$ mice. (E) Adenomyoepithelioma from a Tm( $\mathrm{Pten}^{-/}$) mouse that features small gland-like spaces surrounded by a highly cellular stroma in response to ablation of the Pten tumor suppressor gene. Note the reddish polar cytoplasm characteristic of the tumor cells. (F) A complex Type P tumor in a Tg(Wnt2) mouse illustrating the intricate growth patterns associated with uncontrolled overactivity in the canonical Wnt pathway. Note the central ductal structure with various neoplastic masses at the periphery. All figures were digitally captured using whole-slide imaging of hematoxylin and eosin-stained slides using the 10x or 20x objective; figures have been cropped to a similar size for ready comparison.

signatures can therefore be linked to particular structural phenotypes. Furthermore, the most important molecular determinants in defining the ultimate anatomy of malignant breast tumors rests within the original genetic errors that are expressed in preneoplastic or non-invasive neoplastic lesions such as ductal carcinoma in situ in humans as well as mammary intraepithelial neoplasia in mice [23]. 
Genotype-specific phenotypes have been extended to include entire pathways [24]. An example of this capacity is the combined members of the Wnt signaling pathway $[25,26]$. In the canonical Wnt pathway, the many Wnt ligands bind their receptors to stabilize $\beta$-catenin, allowing it to enter the nucleus to regulate the transcription of target genes that control cell fate and maintain the pluripotency of adult stem cells. Uncontrolled canonical Wnt signaling is a hallmark of cancer. In the mouse mammary gland, tumors resulting from disruption of the Wnt pathway (Wnt tumors) exhibit complex and heterogeneous phenotypes comprised of intermingled epithelial and mesenchymal derivatives (Figure 1F).

Linking the expression of specific oncogenes to neoplasm development provided significant impetus to the notion of personalized molecular therapy. The basis of this concept is that tumors will regress if the initiating oncogene(s) is targeted with the appropriate drug. This premise was soon dispelled, however, by evidence in the mouse that certain oncogene-derived tumors frequently escape their oncogene addiction [27]. Although sobering, this escape from oncogene addiction has also provided an opportunity to explore one of the central problems in clinical oncology - the drug-resistant tumor. How do addicted tumors become drug resistant?

Additional acquired mutations in neoplasms from various tissues represent an obvious answer to this question. For example, human leukemias resistant to the tyrosine kinase inhibitor imatinib are associated with a mutant $A B L 1$ (c-Abl) proto-oncogene [28]. Mouse tumors with $M y c$ mutations that were oncogene independent frequently have an activated Hras (K-ras) gene [29]. However, other mechanisms of enhanced malignancy, metastasis, and tumor resistance have emerged recently that also deserve consideration - namely, phenotypic plasticity and CSC.

\section{Gene addiction, epithelial-to-mesenchymal transition, and phenotypic plasticity in breast cancer} Epithelial-to-mesenchymal transition is a common breast cancer phenotype

Escape from oncogene addiction was observed in GEMs that developed mammary tumors despite having lost expression of the oncogenic transgene. The neoplastic mammary gland epithelium formed tumors with many histomorphologic appearances. One category first described in mouse models is the carcinosarcoma, now classified generically as an EMT tumor [7,30]. These masses are of epithelial origin but contain a substantial spindle cell component (Figure 2).

During the first half of the twentieth century, these mixed neoplasms were believed to be artifacts of transplanting tumor tissue or cultured tumor cells into allogenic mice [30]. More recent research indicates that
EMT tumors represent intraneoplastic dedifferentiation to a more embryonic state, where tumor cells have lost their pure epithelial attributes and gained some mesenchymal properties [31]. Contrary views to this premise have been expressed [32].

During both embryogenesis and tumor formation, EMT is characterized by transformation of plump epithelium into fusiform (spindle-shaped) mesenchyme [31]. The EMT process has been described in detail in both mouse mammary development and tumorigenesis (see reviews in [33]). The process encompasses gradual disruption of epithelial architecture, resulting in discontinuity of basement membranes, loss of cellular cohesion, altered apico-basal polarity, and assumption of spindloid cellular profiles. In addition to having altered morphology, spindle cells in mixed tumors express both epithelial (for example, cytokeratins) and mesenchymal (for example, fibronectin, smooth muscle actin, vimentin) cytoskeleton components, although the extent of marker expression tends to vary from region to region (Figure 2) $[7,34]$. The morphologic continuum observed in such tumors probably reflects the ability of neoplastic mouse mammary epithelium to divide into daughter cells with distinct phenotypes: epithelioid and spindloid [29]. Of note is that the proportion between the two components has serious implications in proliferation and invasiveness of many cancers, especially those of the mouse mammary gland [34]. In human breast cancer, however, there is little agreement about exactly what constitutes EMT tumorigenesis [7,35]. Currently, the presence of EMT in human breast cancers is largely established by specific EMT signatures on gene expression arrays with little attention to phenotype.

The occurrence of EMT within human breast tumors has been linked with malignant transformation and enhanced local and vascular invasiveness, and may reflect the partial dedifferentiation of tumor cells [36]. Interestingly, it appears that metastatic tumor cells undergo EMT to invade the vasculature and then rapidly restore an epithelial phenotype via a reverse mesenchymal-to-epithelial transition (MET) to implant successfully at distant sites [37-39]. Active, bidirectional phenotypic plasticity in human EMT is therefore associated with enhanced malignancy, distant dispersal, and poor prognosis [40].

The biological behavior of human and mouse EMT tumors in the mammary gland is not always identical. Mouse EMT tumors that arise spontaneously or develop from tissue culture transplants are locally aggressive but do not metastasize [7]. In contrast, EMT in the human breast is associated with widespread metastasis and is a strong indicator of a poor prognosis [40]. Several explanations for this divergence between species have been postulated. The most obvious is that the morphologic similarity between EMT tumors from humans and from 


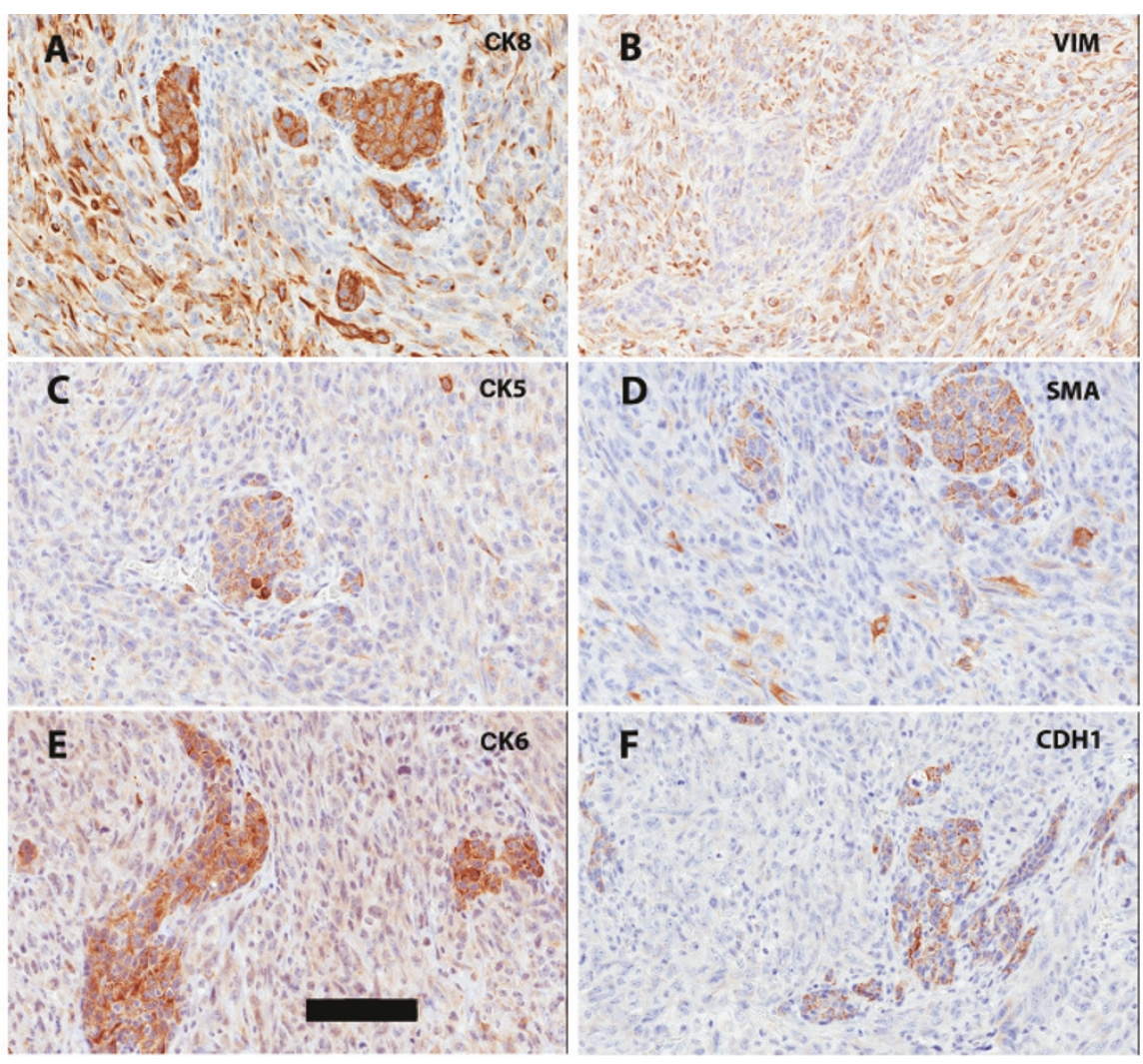

Figure 2. Immunohistochemical phenotypes of epithelial-to-mesenchymal transition tumors in the mouse mammary gland in $\operatorname{Tm}\left(\right.$ Stat $\left.^{-1^{--}}\right)$mice. Immunohistochemistry for various breast cell markers in serial sections of a mouse epithelial-to-mesenchymal transition (EMT) mammary tumor showing both epithelial and spindle cell components. Left: Cytokeratin (CK) staining for three epithelial markers: (A) luminal CK8/18, (C) basal CK5, and (E) progenitor CK6 cells. Right: Staining for two mesenchymal markers, (B) vimentin (VIM) and (D) smooth muscle actin (SMA), and (F) the epithelial junctional complex marker cadherin-1 (CDH1). (A), (B) The images are arranged to highlight the dual CK-VIM staining pattern of EMT tumors. The presence of (C), (D) basal cell antigens and (E) progenitor cell CK in conjunction with (F) loss of CDH1 characterizes the malignant breast epithelial population. All images were captured from whole-slide images acquired with the Aperio ScanScope XT (Aperio, Carlsbad, CA, USA) using the 20x objective. All markers were detected using an indirect immunoperoxidase procedure with diaminobenzidine as the chromagen and hematoxylin as the counterstain. (E) Bar = $100 \mu \mathrm{m}$. The $\operatorname{Tm}\left(S_{t a t 1^{--}}\right)$mice were kindly provided by Dr RD Schreiber [109].

mice may represent a random happening, rather than an indication of shared molecular pathways. Supporting this premise is the fact that the transcriptional repressor SNAI1 (SNAIL), a major regulator of EMT, is overexpressed in highly metastatic human breast cancers [41] but is decreased in metastasis of mice [34]. Another possibility is that mouse EMT spindle tumors represent a terminally differentiated lesion, and thus are not capable of metastasis [42]. If the latter proves true, development of therapeutic agents to induce terminal differentiation may represent a viable therapeutic strategy for human breast cancer patients.

\section{$\mathrm{CDH} 1$ non-oncogene addiction defines the phenotype of breast tumors \\ Repression of $\mathrm{CDH} 1$ is the non-oncogene addiction that drives epithelial-to-mesenchymal transition}

One of the key molecular examples of NOA in human breast carcinomas is the association between the EMT phenotype and altered cell-to-cell adhesion due to reduced $C D H 1$ expression (Figure 2F) [39,42]. Like many of the NOA genes, $C D H 1$ interacts with multiple signaling pathways. Because of its apparent central role in human and mouse EMT tumorigenesis, $C D H 1$ perturbations will be discussed in detail as a prototype for NOA in mammary gland neoplasia.

CDH1 is a major component of adherens and tight junctional complexes. Loss of heterozygosity for $\mathrm{CDH} 1$ was first described in a unique breast cancer subtype, the lobular carcinoma, which is characterized by single files of epithelial tumor cells infiltrating dense fibrous stroma (Figure 1B). Provocatively, GEM with null mutations of both Cdh1 and Trp53 targeted to the mammary gland developed breast tumors that are an exact phenocopy of human lobular carcinoma (Figure 1A,B) [43]. Reduced CDH1 expression may reflect gene inactivation via mutation [16], but more often results from epigenetic downregulation by $\mathrm{CDH1}$ promoter hypermethylation [44] or 
from dysregulated $C D H 1$ transcriptional repression $[42,45]$.

Numerous molecules have been implicated in transient CDH1 repression. Prominent examples include ligands that act via serine/threonine kinase receptors, such as transforming growth factor beta, or tyrosine kinase receptors, such as epidermal growth factor, fibroblast growth factor, hepatocyte growth factor, insulin-like growth factor, platelet-derived growth factor, and vascular endothelial growth factor. Expression of $C D H 1$ is also controlled by many transcription factors, including some members of the forkhead box (for example, FOXC1, FOXC2), basic helix-loop-helix (for example, TWIST1), and zinc finger (for example, SNAI1 (SNAIL), SNAI2 (SLUG), ZEB1) transcription factor families [46,47], as well as by certain cytokines, such as IL-6 [48] and chemokine (C-X-C motif) ligand-12 (formerly termed stromal cell-derived factor-1) [49].

These factors and the signaling pathways they affect often operate synergistically with each other, and with other molecules. Activation of NOTCH1, an important promoter of tumor angiogenesis, functions together with SNAI1-induced CDH1 repression to promote breast cancer metastasis [50], while vascular endothelial growth factor cooperates by boosting SNAI1 expression [51]. Reduction of $C D H 1$ levels by fibroblast growth factor-1 drives malignant transformation and EMT by inducing matrix metalloproteinase-3, the activity of which promotes increased tumor cell motility [52]. Inhibition of CDH1 and SNAI1 is mediated by feedback from other proteins, such as downregulation of SNAI1 levels by glycogen synthase kinase-3 beta, which is in turn regulated by the canonical Wnt pathway $[53,54]$ or by small inhibitory microRNAs [55]. Some of these molecules are useful prognostic markers in human breast cancer, including $\mathrm{C}-\mathrm{X}-\mathrm{C}$ chemokine receptor type 4 , which binds chemokine (C-X-C motif) ligand-12 [49], and SNAI1 [41]. Many of these same factors are controlled via the hedgehog signaling pathway [56], suggesting that hedgehog may also impact $C D H 1$ expression in breast cancer.

Suppression of $C D H 1$ is also associated with steroid hormone-responsive pathways. For example, estrogen receptor (ER)-positive tumors may develop an enhanced metastatic potential and become resistant to estrogen blockers (for example, tamoxifen) because C-X-C chemokine receptor type 4-mediated signaling increases mitogen-activated protein kinase activity, which ultimately represses $C D H 1[57,58]$. Androgen receptor signaling, when combined with DNA modifications made by histone deacetylase-1, downregulates $C D H 1$ in neoplastic breast epithelial cells, thereby impelling EMT and metastasis [59]. The impact of $C D H 1$ in EMT is accompanied by reduced $E R \alpha$ (that is, ESR1) transcription, which is regulated by SNAI1 [60] and SNAI2 [61]; these two transcription factors are regulated reciprocally by ER $\alpha$. Interestingly, ER $\alpha$ expression in EMT is also found in the cytoplasm rather than exhibiting an exclusive localization to the nucleus as occurs in normal breast tissue [62]; the functional implications of this displacement are unknown.

The influence of steroid hormones in breast cancer is not limited to the neoplastic epithelium. Carcinomaassociated fibroblasts express aromatase, an enzyme that augments in situ estrogen production, thereby providing carcinoma-associated fibroblasts with better tumorpromoting capabilities that are not found in normal fibroblasts in non-neoplastic breast tissue [63]. This capability probably renders the neoplastic microenvironment more suitable for the survival and expansion of the breast carcinoma cells.

EMT in the context of malignant transformation obviously involves other mechanisms besides CDH1 represssion. One common finding is cadherin switching, where CDH1 is replaced by another type (usually CDH2 (also called $\mathrm{N}$-cadherin) or $\mathrm{CDH} 11$ ), resulting in increased cellular mobility $[64,65]$. Altered cadherins in tumors can be used as markers for EMT [64]. Furthermore, other junctional complex components involved in epithelial differentiation, such as claudins, occludins, and plakophilins, are also altered in breast cancer, especially along the invasive front [66]. As with $\mathrm{CDH} 1$, these other junctional proteins are also repressed by transcription factors of the basic helix-loop-helix and zinc finger families $[42,45]$. EMT may also result from disrupted interactions between integrins on neoplastic cells and their ligands within the basal lamina and/or extracellular matrix [67]. Alterations in cell-stromal interactions promote local invasion and facilitate metastasis. Additionally, mutations of the tumor suppressor gene Trp53 in GEM result in EMT [68], possibly via interference by Twist1 [69]. Mutations of the human homolog gene TP53 are a common feature in breast carcinoma in humans but are not always associated with EMT [70].

Finally, current thinking in the research community is that a recently identified breast tumor genotype, claudin $^{\text {low }}$, develops EMT as a prominent and reproducible feature $[71,72]$. The expression level of various claudins in primary human breast cancers is usually higher than that of their regional lymph node metastases, suggesting that claudin reductions may contribute to tumor progression [73]. To our knowledge, the relationship between the claudin ${ }^{\text {low }}$ genotype and altered expression of $C D H 1$, or other molecules that can modify $C D H 1$ levels, remains to be clarified. Nonetheless, claudin ${ }^{\text {low }}$ tumors are associated with the core molecular signature of EMT - for example, downregulation of $C D H 1$ with concomitant upregulation of Goosecoid (GSC, a homeobox gene), SNAI2, transforming growth factor beta 1 and TWIST1 - suggesting 
a probable interaction between the pathways regulating CDH1 and claudin [47].

In summary, $C D H 1$ is considered a central figure in clinical EMT tumorigenesis. As documented above, however, extensive, complex molecular interactions between CDH1 and the other key molecules are difficult to evaluate, let alone validate. The complexity coupled with the early state of NOA investigations guarantees conflicting notions about which are the key molecules driving the process and obscures mechanistic understanding of the entire process. The pathology community will have to continue searching for evidence that the EMT-MET paradigm is more than a molecular illusion.

\section{Restoration of $\mathrm{CDH} 1$ promotes mesenchymal-to-epithelial transition}

Metastatic seeding is the rate-limiting event for carcinoma progression [39]. The current speculation is that EMT is required for initial tumor embolization, but that restoration of the original epithelial phenotype via MET is necessary for invading cancer cells to form viable metastases [74]. The MET process is hence reciprocal to EMT and includes both the reacquisition of an epithelial phenotype with the ability to form glands [74] and also the restoration of the molecular complement indicative of epithelial differentiation, such as $C D H 1$ expression [39].

The molecular mechanisms of MET in breast cancer metastases remain unknown. Recent reports suggest that MET is induced in breast carcinoma cells by many signaling events: binding of signal transducer and activator of transcription-5 to its tyrosine kinase receptor, JAK2 [38]; reduced expression of phosphoglucose isomerase/autocrine motility factor [75]; and inhibition of SRC homology phosphotyrosyl phosphatase-2 (PTNP11 in humans), a vital promitogenic and prosurvival transducer in the epidermal growth factor receptor signaling pathway [76]. All three pathways induce CDH1 expression and downregulate expression of mesenchymal markers (for example, fibronectin, vimentin). The signal transducer and activator of transcription-5/JAK2 pathway also reduces levels of SNAI1, an important $C D H 1$ repressor [38]. In spite of these known complex molecular relationships, the presence of MET has rarely been documented in the clinical setting. It is not clear whether MET occurs in all metastatic clinical situations or whether the microarray and molecular data may reflect associations rather than actual mechanisms.

These proposed events remain mostly conjectural through guilt by association or documentation in rare tumor types. The popular reviews of the metastatic process present cartoons showing individual cells that undergo EMT and migrate through the connective tissue to invade the vasculature and be carried to a distant site where the reverse MET process occurs to ensure colonization. Not many pathologists have seen this phenomenon in traditional diagnostic or research samples [16]. The actual visualization of these events has been provided by Condeelis and coworkers, with intravital microscopy showing tumor cells migrating through the tissue with an escort of macrophages [77,78]. Most direct observations of intravascular malignant cells in standard microscopy, however, reveal these cells on rafts of fibrin clots $[79,80]$ or as non-invasive intravascular emboli [81]. In other words, the clusters of cells that are molecularly able to invade and metastasize are probably small microscopic subsets that do not necessarily represent the entire neoplasm. This observation poses a problem in validating gene expression microarray signatures related to EMT because the overall tumor genetic make-up probably masks these rare events.

\section{Cancer stem cells in breast cancer}

In spite of the speculations of Virchow and Connheim, the stem cell hypothesis became lost in the field effects hypothesis [4], and some medical textbooks of the 1950s taught tumor biology in the terms of dedifferentiation of mature cell populations. However, experimental proof eventually emerged that most cancers were clonal [3]. In mammary tumor biology, Joe Leighton and Barry Pierce provided evidence of a rare stem cell population in mouse mammary tumors that gave rise to neoplasms [3]. The inherent plasticity of the CSC in the context of the mammary gland was discussed in the 1970s by Beatrice Mintz [3]. The ultimate demonstration of plasticity was given by Gail Martin using blastocyts injected with teratocarcinoma cells to produce normal healthy mouse pups [82].

Tumor heterogeneity has become an important theme of breast cancer research, suggesting that tumors consist of multiple clonally derived subpopulations $[57,83,84]$. Large subpopulations of tumor cells are either capable of expansion or are terminally differentiated, while only a small subset of primitive, pluripotent CSC is capable of self-renewal, asymmetrical mitoses, and multilineagespecific differentiation [83].

Human breast CSC are usually associated with a $\mathrm{CD}_{4} 4^{+} / \mathrm{CD} 24^{-/ \text {low }}$ signature [83]. Expression of these surface molecules is affected by numerous genetic and epigenetic factors [85], however, and new markers (for example, aldehyde dehydrogenase-1, multidrug-resistance proteins) are regularly being linked to self-renewability $[83,86,87]$. Accordingly, a definitive molecular phenotype for breast CSC has not been determined.

The origin of breast CSC also remains uncertain. Competing hypotheses are that CSC arise by dedifferentiation of proliferation-competent epithelial cells, or by oncogenic mutations in normal stem cells [88]. At least four genetically distinct breast cancer subtypes have 
been defined by microarray profiling [89], and at least two types of stem cells have been identified within these subtypes - basal progenitors and luminal progenitors [90]. At present, the former population is considered to be a better candidate for breast CSC [83]. Claudin ${ }^{\text {low }}$ tumors, however, have been hypothesized to arise from an even earlier breast epithelial precursor than either basal-like or luminal progenitor cells [71,72]. Furthermore, some evidence suggests that the CSC are present in the early premalignant stages [91].

Comparable stem cell subsets have been defined in mouse mammary tumors, which share many conserved genes with their human counterparts [92]. A recent study in developing (prenatal and early postnatal) mice suggests that different cohorts of cultured, poorly differentiated breast epithelial cells exhibit distinct patterns of cytokeratin (CK) expression. In particular, CK5 occurs in basal cells, CK6 marks multipotent progenitor cells in the basal layer, CK8 is found in luminal cells, and CK14 is confined to myoepithelial cells; small populations are positive for both CK6 and CK14 [93] (Figure 2). The $\mathrm{CK}^{+}$breast epithelium population has been both proposed [94] and denied [95] as another marker for mammary gland stem cells. Importantly, unique subpopulations of CSC appear capable of giving rise to different breast cancer variants in both humans and mice [92]. If some or all of the above-mentioned CK patterns are eventually confirmed, these intermediate filaments could be used as molecular indicators for functionally unique breast epithelial cell types.

Lastly, breast CSC are presumed to thrive only in specific microenvironmental niches [57] due to the availability of the many supporting factors that affect stem cell numbers and function. For example, the populations of both normal stem cells and CSC are characterized by phosphatidylinositol 3-kinase activation resulting from HER2 amplification [96] in conjunction with decreased PTEN expression and decreased canonical Wnt/ $\beta$-catenin interactions [97]. Signaling via Sonic Hedgehog [98] or NOTCH [99] also promotes selfrenewal of cultured human mammary stem cells. The presence of transforming growth factor beta augments CSC motility and invasiveness [100]. The tumor microenvironment is also important in CSC biology because many factors that support cancer growth, hormone resistance, immune evasion, and metastasis are produced by stromal cells, such as chemokine ( $\mathrm{C}-\mathrm{X}-\mathrm{C}$ motif) ligand-12 by mesenchymal stem cells [83,101] and carcinoma-associated fibroblasts [102].

\section{Phenotypic plasticity is linked to cancer stem cell generation and competence}

Local invasiveness and metastasis are governed by numerous factors, including the heterogeneity of cell subsets within the primary tumor $[57,83,84]$, the interaction of tumor cells with the microenvironment [103], and the unique combination of cell signaling factors affecting the migrating metastatic cells (seeds) and the colonization sites (soil) [104]. The tendency to undergo EMT is one such factor, as this process generates multiple epithelial subsets with divergent states of stemness relative to more differentiated cells [105].

Several lines of evidence support the link between EMT and CSC in breast cancer. First, EMT induction endows normal and transformed mammary epithelial cells with stem cell properties, including the ability to self-renew and efficiently initiate tumors [106]. Second, neoplastic breast epithelium undergoing EMT exhibits a $\mathrm{CD}_{4} 4^{+} / \mathrm{CD} 24^{-/ \text {low }}$ genotype that is consistent with the proposed molecular signature of breast CSC [72,107]; this signature has also been linked to the claudin ${ }^{\text {low }}$ genotype [72]. Examples include the induction of CSC through EMT-driven activation of the Ras-mitogenactivated protein kinase pathway [85] as well as via overexpression of SNAI1 and TWIST, key regulators of EMT [46].

Existing data suggest that the EMT program can trigger generation of breast CSC. One intriguing possibility is that EMT foments inherently different CSC subtypes that are responsible for the initiation and progression of breast cancers with divergent patterns of progression and metastasis. The divergent patterns are exemplified by the ability of one oncogene $(M y c)$ to generate mouse mammary tumors with different phenotypes [108]. Given the obvious phenotypic complexity of human breast cancer, considerable work correlating EMT and phenotypic plasticity, specific gene addictions, and CSC biology will be required to produce innovative therapies to attack this dreaded disease.

\section{Conclusion}

Therapeutic approaches to breast cancer increasingly rely on personalized approaches that identify and attack specific genes, proteins, or pathways. Such targeted treatments depend on the concept of gene addiction (to overexpressed oncogenes and/or reduced non-oncogenes) as a driving force in tumor initiation and progression. Drugs aimed at particular genes have shown some promise, but tumor plasticity - perhaps residing in the rare cancerinitiating stem cells - frequently leads to drug resistance and relapse, preventing a patient moving from temporary remission to permanent cure. Ultimate success in breast cancer therapy will rely on our recognition, understanding, and control of CSC and the gene addictions that control phenotypic plasticity of breast cancers.

\section{Abbreviations}

CK, cytokeratin; CSC, cancer stem cells; EMT, epithelial-to-mesenchymal transition; ER, estrogen receptor; GEM, genetically engineered mouse; 
IL, interleukin; MET, mesenchymal-to-epithelial transition; NOA, non-oncogene addiction; TSG, tumor-suppressor gene.

\section{Competing interests}

The authors declare that they have no competing interests.

\section{Acknowledgements}

The present work was supported in part by grant U01 CA141582 to RDC from the National Cancer Institute's Mouse Models of Human Cancers Consortium.

\section{Author details}

'Department of Pathology, Center for Comparative Medicine, University of California, Davis, County Road 98 and Hutchison Drive, Davis, CA 95616, USA. 2Pathology Department, Genentech, Inc., 1 DNA Way, South San Francisco, CA 94080-4990, USA. ${ }^{3}$ GEMpath, Inc., 2867 Humboldt Cir., Longmont, CO 80503, USA.

Published: 25 October 2011

\section{References}

1. Cardiff RD: Epilog: comparative medicine, one medicine and genomic pathology. Breast Dis 2007, 28:107-110.

2. Cardiff RD, Ward JM, Barthold SW: 'One medicine - one pathology': are veterinary and human pathology prepared? Lab Invest 2008, 88:18-26.

3. Cardiff RD, Kenney N: A compendium of the mouse mammary tumor biologist: from the initial observations in the house mouse to the development of genetically engineered mice. Cold Spring Harb Perspect Biol 2011, 3:1-12.

4. Rather L: The Genesis of Cancer: A Study in the History of Ideas. Baltimore, MD: Johns Hopkins University Press; 1978.

5. Nieto MA: Epithelial-mesenchymal transitions in development and disease: old views and new perspectives. Int J Dev Bio/ 2009, 53:1541-1547.

6. Thiery JP, Acloque H, Huang RY, Nieto MA: Epithelial-mesenchymal transitions in development and disease. Cell 2009, 139:871-890.

7. Cardiff RD: The pathology of EMT in mouse mammary tumorigenesis. J Mammary Gland Biol Neoplasia 2010, 15:225-233.

8. Weinstein IB: Cancer. Addiction to oncogenes - the Achilles heal of cancer. Science 2002, 297:63-64. Comment in Science 2002, 297:102-104.

9. Jonkers J, Berns A: Oncogene addiction: sometimes a temporary slavery. Cancer Cell 2004, 6:535-538.

10. Jain M, Arvanitis C, Chu K, Dewey W, Leonhardt E, Trinh M, Sundberg CD, Bishop JM, Felsher DW: Sustained loss of a neoplastic phenotype by brief inactivation of MYC. Science 2002, 297:102-104.

11. Weinstein IB, Joe A: Oncogene addiction. Cancer Res 2008, 68:3077-3080.

12. Hynes NE, Stoelzle T: Key signalling nodes in mammary gland development and cancer: Myc. Breast Cancer Res 2009, 11:210.

13. Taneja P, Frazier DP, Kendig RD, Maglic D, Sugiyama T, Kai F, Taneja NK, Inoue K: MMTV mouse models and the diagnostic values of MMTV-like sequences in human breast cancer. Expert Rev Mol Diagn 2009, 9:423-440.

14. Luo J, Solimini NL, Elledge SJ: Principles of cancer therapy: oncogene and non-oncogene addiction. Cell 2009, 136:823-837. Erratum in Cell 2009, 138:807.

15. Cardiff RD, Sinn E, Muller W, Leder P: Transgenic oncogene mice. Tumor phenotype predicts genotype. Am J Pathol 1991, 139:495-501.

16. Berx G, Van Roy F: The E-cadherin/catenin complex: an important gatekeeper in breast cancer tumorigenesis and malignant progression. Breast Cancer Res 2001, 3:289-293.

17. Ursini-Siegel J, Schade B, Cardiff RD, Muller WJ: Insights from transgenic mouse models of ERBB2-induced breast cancer. Nat Rev Cancer 2007, 7:389-397.

18. Steeg PS, Ouatas T, Halverson D, Palmieri D, Salerno M: Metastasis suppressor genes: basic biology and potential clinical use. Clin Breast Cancer 2003, 4:51-62.

19. Shevde LA, Welch DR: Metastasis suppressor pathways - an evolving paradigm. Cancer Lett 2003, 198:1-20.

20. Da Silva L, Lakhani SR: Pathology of hereditary breast cancer. Mod Pathol 2010, 23:S46-S51.

21. D'Assoro AB, Leontovich A, Amato A, Ayers-Ringler JR, Quatraro C, Hafner K, Jenkins RB, Libra M, Ingle J, Stivala F, Galanis E, Salisbury JL: Abrogation of p53 function leads to metastatic transcriptome networks that typify tumor progression in human breast cancer xenografts. Int J Oncol 2010,
37:1167-1176.

22. Shackney SE, Shankey TV: Common patterns of genetic evolution in human solid tumors. Cytometry 1997, 29:1-27.

23. Namba R, Maglione JE, Davis RR, Baron CA, Liu S, Carmack CE, Young LJ, Borowsky AD, Cardiff RD, Gregg JP: Heterogeneity of mammary lesions represent molecular differences. BMC Cancer 2006, 6:275.

24. Rosner A, Miyoshi K, Landesman-Bollag E, Xu X, Seldin DC, Moser AR, MacLeod CL, Shyamala G, Gillgrass AE, Cardiff RD: Pathway pathology: histological differences between ErbB/Ras and Wnt pathway transgenic mammary tumors. Am J Patho/ 2002, 161:1087-1097.

25. Miyoshi K, Rosner A, Nozawa M, Byrd C, Morgan F, Landesman-Bollag E, Xu X Seldin DC, Schmidt EV, Taketo MM, Robinson GW, Cardiff RD, Hennighausen L: Activation of different Wnt/ß-catenin signaling components in mammary epithelium induces transdifferentiation and the formation of pilar tumors. Oncogene 2002, 21:5548-5556.

26. Mikels AJ, Nusse R: Wnts as ligands: processing, secretion and reception. Oncogene 2006, 25:7461-7468

27. Felsher DW: Tumor dormancy and oncogene addiction. APMIS 2008, 16:629-637.

28. Sawyers CL: Shifting paradigms: the seeds of oncogene addiction. Nat Med 2009, 15:1158-1161.

29. D'Cruz CM, Gunther EJ, Boxer RB, Hartman JL, Sintasath L, Moody SE, Cox JD, Ha SI, Belka GK, Golant A, Cardiff RD, Chodosh LA: c-MYC induces mammary tumorigenesis by means of a preferred pathway involving spontaneous Kras2 mutations. Nat Med 2001, 7:235-239.

30. Cardiff RD, Kenney N: Mouse mammary tumor biology: a short history. Adv Cancer Res 2007, 98:53-116.

31. Berx G, Raspé E, Christofori G, Thiery JP, Sleeman JP: Pre-EMTing metastasis? Recapitulation of morphogenetic processes in cancer. Clin Exp Metastasis 2007, 24:587-597.

32. Tarin D, Thompson EW, Newgreen DF: The fallacy of epithelial mesenchymal transition in neoplasia. Cancer Res 2005, 65:5996-6000; discussion 6000-6001.

33. J Mammary Gland Biol Neoplasia 2010, 15:Issue 2 [containing eight articles]

34. Damonte P, Gregg JP, Borowsky AD, Keister BA, Cardiff RD:

EMT tumorigenesis in the mouse mammary gland. Lab Invest 2007 , 87:1218-1226.

35. Micalizzi DS, Farabaugh SM, Ford HL: Epithelial-mesenchymal transition in cancer: parallels between normal development and tumor progression. J Mammary Gland Biol Neoplasia 2010, 15:117-134.

36. Thiery JP: Epithelial-mesenchymal transitions in development and pathologies. Curr Opin Cell Biol 2003, 15:740-746.

37. Hugo H, Ackland ML, BlickT, Lawrence MG, Clements JA, Williams ED, Thompson EW: Epithelial-mesenchymal and mesenchymal-epithelial transitions in carcinoma progression. J Cell Physio/ 2007, 213:374-383.

38. Sultan AS, Brim H, Sherif ZA: Co-overexpression of Janus kinase 2 and signal transducer and activator of transcription 5a promotes differentiation of mammary cancer cells through reversal of epithelial-mesenchymal transition. Cancer Sci 2008, 99:272-279.

39. Wells A, Yates C, Shepard CR: E-cadherin as an indicator of mesenchymal to epithelial reverting transitions during the metastatic seeding of disseminated carcinomas. Clin Exp Metastasis 2008, 25:621-628.

40. Karreth F, Tuveson DA: Twist induces an epithelial-mesenchymal transition to facilitate tumor metastasis. Cancer Biol Ther 2004, 3:1058-1059.

41. Blanco MJ, Moreno-Bueno G, Sarrio D, Locascio A, Cano A, Palacios J, Nieto MA: Correlation of Snail expression with histological grade and lymph node status in breast carcinomas. Oncogene 2002, 21:3241-3246.

42. Radaelli E, Damonte P, Cardiff RD: Epithelial-mesenchymal transition in mouse mammary tumorigenesis. Future Oncol 2009, 5:1113-1127.

43. Derksen PW, Liu X, Saridin F, van der Gulden H, Zevenhoven J, Evers B, van Beijnum JR, Griffioen AW, Vink J, Krimpenfort P, Peterse JL, Cardiff RD, Berns A, Jonkers J: Somatic inactivation of E-cadherin and p53 in mice leads to metastatic lobular mammary carcinoma through induction of anoikis resistance and angiogenesis. Cancer Cell 2006, 10:437-449.

44. Caldeira JR, Prando EC, Quevedo FC, Neto FA, Rainho CA, Rogatto SR: CDH1 promoter hypermethylation and $\mathrm{E}$-cadherin protein expression in infiltrating breast cancer. BMC Cancer 2006, 6:48.

45. Peinado $H$, Olmeda D, Cano A: Snail, Zeb and bHLH factors in tumour progression: an alliance against the epithelial phenotype? Nat Rev Cancer 2007, 7:415-428.

46. Foubert E, De Craene B, Berx G: Key signalling nodes in mammary gland 
development and cancer. The Snail1-Twist1 conspiracy in malignant breast cancer progression. Breast Cancer Res 2010, 12:206.

47. Taube JH, Herschkowitz Jl, Komurov K, Zhou AY, Gupta S, Yang J, Hartwell K, Onder TT, Gupta PB, Evans KW, Hollier BG, Ram PT, Lander ES, Rosen JM, Weinberg RA, Mani SA: Core epithelial-to-mesenchymal transition interactome gene-expression signature is associated with claudin-low and metaplastic breast cancer subtypes. Proc Natl Acad Sci U S A 2010, 107:15449-15454. Erratum in Proc Natl Acad SciU S A 2010, 107:19132.

48. Sullivan NJ, Sasser AK, Axel AE, Vesuna F, Raman V, Ramirez N, Oberyszyn TM, Hall BM: Interleukin-6 induces an epithelial-mesenchymal transition phenotype in human breast cancer cells. Oncogene 2009, 28:2940-2947.

49. Burger JA, Kipps TJ: CXCR4: a key receptor in the crosstalk between tumor cells and their microenvironment. Blood 2006, 107:1761-1767.

50. Leong KG, Niessen K, Kulic I, Raouf A, Eaves C, Pollet I, Karsan A: Jagged1mediated Notch activation induces epithelial-to-mesenchymal transition through Slug-induced repression of E-cadherin. J Exp Med 2007, 204:2935-2948.

51. Wanami LS, Chen HY, Peiró S, García de Herreros A, Bachelder RE: Vascular endothelial growth factor-A stimulates Snail expression in breast tumor cells: implications for tumor progression. Exp Cell Res 2008, 314:2448-2453.

52. Xian W, Schwertfeger KL, Vargo-Gogola T, Rosen JM: Pleiotropic effects of FGFR1 on cell proliferation, survival, and migration in a 3D mammary epithelial cell model. J Cell Biol 2005, 171:663-673.

53. Yook Jl, Li XY, Ota I, Hu C, Kim HS, Kim NH, Cha SY, Ryu JK, Choi YJ, Kim J, Fearon ER, Weiss SJ: A Wnt-Axin2-GSK3b cascade regulates Snail1 activity in breast cancer cells. Nat Cell Biol 2006, 82:1398-1406.

54. Prasad CP, Rath G, Mathur S, Bhatnagar D, Parshad R, Ralhan R: Expression analysis of E-cadherin, Slug and GSK3b in invasive ductal carcinoma of breast. BMC Cancer 2009, 9:325.

55. Le Quesne J, Caldas C: Micro-RNAs and breast cancer. Mol Oncol 2010, 4:230-241.

56. Katoh Y, Katoh M: Hedgehog target genes: mechanisms of carcinogenesis induced by aberrant hedgehog signaling activation. Curr Mol Med 2009, 9:873-886.

57. Croker AK, Allan AL: Cancer stem cells: implications for the progression and treatment of metastatic disease. J Cell Mol Med 2008, 12:374-390.

58. Rhodes LV, Short SP, Neel N, Salvo VA, Zhu Y, Elliott S, Wei Y, Yu D, Sun M, Muir SE, Fonseca JP, Bratton MR, Segar C, Tilghman SL, Sobolik-Delmaire T, Horton LW, Zaja-Milatovic S, Collins-Burow BM, Wadsworth S, Beckman BS, Wood CE, Fuqua SA, Nephew KP, Dent P, Worthylake RA, Curiel TJ, Hung MC, Richmond A, Burow ME: Cytokine receptor CXCR4 mediates estrogen-independent tumorigenesis, metastasis, and resistance to endocrine therapy in human breast cancer. Cancer Res 2011, 71:603-613.

59. Liu Y-N, Liu Y, Lee H-J, Hsu Y-H, Chen J-H: Activated androgen receptor downregulates $\mathrm{E}$-cadherin gene expression and promotes tumor metastasis. Mol Cell Biol 2008, 28:7096-7108.

60. Dhasarathy A, Kajita M, Wade PA: The transcription factor snail mediates epithelial to mesenchymal transitions by repression of estrogen receptora. Mol Endocrinol 2007, 21:2907-2918.

61. Ye Y, Xiao Y, Wang W, Yearsley K, Gao J, Shetuni B, Barsky SH: ERa signaling through slug regulates E-cadherin and EMT. Oncogene 2010, 29:1451-1462.

62. Radaelli E, Arnold A, Papanikolaou A, Garcia-Fernandez RA, Mattiello S, Scanziani E, Cardiff RD: Mammary tumor phenotypes in wild-type aging female FVB/N mice with pituitary prolactinomas. Vet Pathol 2009, 46:736-745.

63. Yamaguchi Y, Hayashi S: Estrogen-related cancer microenvironment of breast carcinoma. Endocr J 2009, 56:1-7.

64. Sarrió D, Rodriguez-Pinilla SM, Hardisson D, Cano A, Moreno-Bueno G Palacios J: Epithelial-mesenchymal transition in breast cancer relates to the basal-like phenotype. Cancer Res 2008, 68:989-997.

65. Nieman MT, Prudoff RS, Johnson KR, Wheelock MJ: N-cadherin promotes motility in human breast cancer cells regardless of their E-cadherin expression. J Cell Biol 1999, 147:631-644.

66. Aigner K, Descovich L, Mikula M, Sultan A, Dampier B, Bonné S, van Roy F, Mikulits W, Schreiber M, Brabletz T, Sommergruber W, Schweifer N, Wernitznig A, Beug H, Foisner R, Eger A: The transcription factor ZEB1 (deltaEF1) represses Plakophilin 3 during human cancer progression. FEBS Lett 2007, 581:1617-1624.

67. Maschler S, Wirl G, Spring H, Bredow DV, Sordat I, Beug H, Reichmann E: Tumor cell invasiveness correlates with changes in integrin expression and localization. Oncogene 2005, 24:2032-2041.
68. Cardiff RD: Epithelial to mesenchymal transition tumors: fallacious or Snail's pace? Clin Cancer Res 2005, 11:8534-8537.

69. Shiota M, Izumi H, Onitsuka T, Miyamoto N, Kashiwagi E, Kidani A, Hirano G Takahashi M, Naito S, Kohno K: Twist and p53 reciprocally regulate target genes via direct interaction. Oncogene 2008, 27:5543-5553.

70. Angèle S, Jones C, Reis Filho JS, Fulford LG, Treilleux I, Lakhani SR, Hall J: Expression of ATM, p53, and the MRE11-Rad50-NBS1 complex in myoepithelial cells from benign and malignant proliferations of the breast. J Clin Pathol 2004, 57:1179-1184.

71. Creighton CJ, Chang JC, Rosen JM: Epithelial-mesenchymal transition (EMT) in tumor-initiating cells and its clinical implications in breast cancer. J Mammary Gland Biol Neoplasia 2010, 15:253-260.

72. Hennessy BT, Gonzalez-Angulo AM, Stemke-Hale K, Gilcrease MZ, Krishnamurthy S, Lee JS, Fridlyand J, Sahin A, Agarwal R, Joy C, Liu W, Stivers D, Baggerly K, Carey M, Lluch A, Monteagudo C, He X, Weigman V, Fan C, Palazzo J, Hortobagyi GN, Nolden LK, Wang NJ, Valero V, Gray JW, Perou CM, Mills GB: Characterization of a naturally occurring breast cancer subset enriched in epithelial-to-mesenchymal transition and stem cell characteristics. Cancer Res 2009, 69:4116-4124.

73. Szasz AM, Tokes AM, Micsinai M, Krenacs T, Jakab C, Lukacs L, Nemeth Z, Baranyai Z, Dede K, Madaras L, Kulka J: Prognostic significance of claudin expression changes in breast cancer with regional lymph node metastasis. Clin Exp Metastasis 2011, 28:55-63.

74. van der Pluijm G: Epithelial plasticity, cancer stem cells and bone metastasis formation. Bone 2011, 48:37-43

75. Funasaka T, Hogan V, Raz A: Phosphoglucose isomerase/autocrine motility factor mediates epithelial and mesenchymal phenotype conversions in breast cancer. Cancer Res 2009, 69:5349-5356

76. Zhou XD, Agazie YM: Inhibition of SHP2 leads to mesenchymal to epithelial transition in breast cancer cells. Cell Death Differ 2008, 15:988-996.

77. Wyckoff JB, Wang Y, Lin EY, Li JF, Goswami S, Stanley ER, Segall JE, Pollard JW, Condeelis J: Direct visualization of macrophage-assisted tumor cell intravasation in mammary tumors. Cancer Res 2007, 67:2649-2656.

78. Kedrin D, Gligorijevic B, Wyckoff J, Verkhusha W, Condeelis J, Segall JE, van Rheenen J: Intravital imaging of metastatic behavior through a mammary imaging window. Nat Methods 2008, 5:1019-1021

79. Wenzel J, Zeisig R, Haider W, Habedank S, Fichtner I: Inhibition of pulmonary metastasis in a human MT3 breast cancer xenograft model by dual liposomes preventing intravasal fibrin clot formation. Breast Cancer Res Treat 2010, 121:13-22.

80. Cardiff RD, Munn RJ, Galvez Jj: The tumor pathology of genetically engineered mice: a new approach to molecular pathology. In The Mouse in Biomedical Research Vol 2: Diseases. 2nd edition. Edited by Fox JG, Barthold SW, Davisson MT, Newcomer CE, Quimby FW, Smith AL. San Diego: Academic Press (Elsevier); 2007:581-622.

81. Sugino T, Kusakabe T, Hoshi N, Yamaguchi T, Kawaguchi T, Goodison S, Sekimata M, Homma Y, Suzuki T: An invasion-independent pathway of blood-borne metastasis: a new murine mammary tumor model. Am $\lrcorner$ Pathol 2002, 160:1973-1980.

82. Martin GR: Teratocarcinomas and mammalian embryogenesis. Science 1980, 209:768-776

83. Patel SA, Ndabahaliye A, Lim P, Milton R, Rameshwar P: Challenges in the development of future treatments for breast cancer stem cells. Breast Cancer (London) 2010, 2:1-11.

84. Raimondi C, Gianni W, Cortesi E, Gazzaniga P: Cancer stem cells and epithelial-mesenchymal transition: revisiting minimal residual disease. Curr Cancer Drug Targets 2010, 10:496-508.

85. Morel AP, Lièvre M, Thomas C, Hinkal G, Ansieau S, Puisieux A: Generation of breast cancer stem cells through epithelial-mesenchymal transition. PLOS ONE 2008, 3:e2888.

86. Ginestier C, Hur MH, Charafe-Jauffret E, Monville F, Dutcher J, Brown M, Jacquemier J, Viens P, Kleer C, Liu S, Schott A, Hayes D, Birnbaum D, Wicha MS, Dontu G: ALDH1 is a marker of normal and malignant human mammary stem cells and a predictor of poor clinical outcome. Cell Stem Cell 2007 1:555-567.

87. Alison MR, Guppy NJ, Lim SM, Nicholson LJ: Finding cancer stem cells: are aldehyde dehydrogenases fit for purpose? J Pathol 2010, 222:335-344.

88. Dittmar T, Nagler C, Schwitalla S, Reith G, Niggemann B, Zänker KS: Recurrence cancer stem cells - made by cell fusion? Med Hypotheses 2009, 73:542-547.

89. González LO, Corte MD, Junquera S, González-Fernández R, del Casar JM, 
García C, Andicoechea A, Vázquez J, Pérez-Fernández R, Vizoso FJ: Expression and prognostic significance of metalloproteases and their inhibitors in luminal A and basal-like phenotypes of breast carcinoma. Hum Pathol 2009, 40:1224-1233.

90. Lim E, Vaillant F, Wu D, Forrest NC, Pal B, Hart AH, Asselin-Labat ML, Gyorki DE, Ward T, Partanen A, Feleppa F, Huschtscha LI, Thorne HJ, Investigators of The Kathleen Cuningham Consortium for Research into Familial Breast Cancer, Fox SB, Yan M, French JD, Brown MA, Smyth GK, Visvader JE, Lindeman GJ: Aberrant luminal progenitors as the candidate target population for basal tumor development in BRCA1 mutation carriers. Nat Med 2009, 15:907-913.

91. Damonte P, Hodgson JG, Chen JQ, Young LJ, Cardiff RD, Borowsky AD: Mammary carcinoma behavior is programmed in the precancer stem cell. Breast Cancer Res 2008, 10:R50.

92. Lim E, Wu D, Pal B, Bouras T, Asselin-Labat ML, Vaillant F, Yagita H, Lindeman GJ, Smyth GK, Visvader JE: Transcriptome analyses of mouse and human mammary cell subpopulations reveal multiple conserved genes and pathways. Breast Cancer Res 2010, 12:R21.

93. Sun P, Yuan Y, Li A, Li B, Dai X: Cytokeratin expression during mouse embryonic and early postnatal mammary gland development. Histochem Cell Biol 2010, 133:213-221.

94. Smith GH, Mehrel T, Roop DR: Differential keratin gene expression in developing, differentiating, preneoplastic, and neoplastic mouse mammary epithelium. Cell Growth Differ 1990, 1:161-170.

95. Mikaelian I, Hovick M, Silva KA, Burzenski LM, Shultz LD, Ackert-Bicknell CL, Cox GA, Sundberg JP: Expression of terminal differentiation proteins defines stages of mouse mammary gland development. Vet Pathol 2006, 43:36-49.

96. Korkaya H, Paulson A, lovino F, Wicha MS: HER2 regulates the mammary stem/progenitor cell population driving tumorigenesis and invasion. Oncogene 2008, 27:6120-6130.

97. Korkaya H, Paulson A, Charafe-Jauffret E, Ginestier C, Brown M, Dutcher J, Clouthier SG, Wicha MS: Regulation of mammary stem/progenitor cells by PTEN/Akt/B-catenin signaling. PLoS Bio/ 2009, 7:e1000121.

98. Liu S, Dontu G, Mantle ID, Patel S, Ahn NS, Jackson KW, Suri P, Wicha MS: Hedgehog signaling and Bmi-1 regulate self-renewal of normal and malignant human mammary stem cells. Cancer Res 2006, 66:6063-6071.

99. Dontu G, Jackson KW, McNicholas E, Kawamura MJ, Abdallah WM, Wicha MS Role of Notch signaling in cell-fate determination of human mammary stem/progenitor cells. Breast Cancer Res 2004, 6:R605-R615.

100. Tan AR, Alexe G, Reiss M: Transforming growth factor-beta signaling: emerging stem cell target in metastatic breast cancer? Breast Cancer Res
Treat 2009, 115:453-495

101. Rhodes LV, Antoon JW, Muir SE, Elliott S, Beckman BS, Burow ME: Effects of human mesenchymal stem cells on ER-positive human breast carcinoma cells mediated through ER-SDF-1/CXCR4 crosstalk. Mol Cancer 2010, 9:295.

102. Mishra PJ, Mishra PJ, Humeniuk R, Medina DJ, Alexe G, Mesirov JP, Ganesan S, Glod JW, Banerjee D: Carcinoma-associated fibroblast-like differentiation of human mesenchymal stem cells. Cancer Res 2008, 68:4331-4339.

103. Langley RR, Fidler IJ: Tumor cell-organ microenvironment interactions in the pathogenesis of cancer metastasis. Endocr Rev 2007, 28:297-321.

104. Andre F, Cabioglu N, Assi H, Sabourin JC, Delaloge S, Sahin A, Broglio K, Spano JP, Combadiere C, Bucana C, Soria JC, Cristofanilli M: Expression of chemokine receptors predicts the site of metastatic relapse in patients with axillary node positive primary breast cancer. Ann Oncol 2006, 17:945-951.

105. Mani SA, Guo W, Liao M, Eaton EN, Ayyanan A, Zhou A, Brooks M, Reinhard F Zhang CC, Shipitsin M, Campbell LL, Polyak K, Brisken C, Yang J, Weinberg RA The epithelial-mesenchymal transition generates cells with properties of stem cells. Cell 2008, 133:704-715.

106. Hollier BG, Evans K, Mani SA: The epithelial-to-mesenchymal transition and cancer stem cells: a coalition against cancer therapies. J Mammary Gland Biol Neoplasia 2009, 14:29-43.

107. Santisteban M, Reiman JM, Asiedu MK, Behrens MD, Nassar A, Kalli KR Haluska P, Ingle JN, Hartmann LC, Manjili MH, Radisky DC, Ferrone S, Knutson $\mathrm{KL}:$ Immune-induced epithelial to mesenchymal transition in vivo generates breast cancer stem cells. Cancer Res 2009, 69:2887-2895.

108. Andrechek ER, Cardiff RD, Chang JT, Gatza ML, Acharya CR, Potti A, Nevins JR: Genetic heterogeneity of Myc-induced mammary tumors reflecting diverse phenotypes including metastatic potential. Proc Natl Acad Sci U S A 2009, 106:16387-16392

109. Meraz MA, White JM, Sheehan KC, Bach EA, Rodig SJ, Dighe AS, Kaplan DH, Riley JK, Greenlund AC, Campbell D, Carver-Moore K, DuBois RN, Clark R, Aguet M, Schreiber RD: Targeted disruption of the Stat1 gene in mice reveals unexpected physiologic specificity in the JAK-STAT signaling pathway. Cell 1996, 84:431-442.

doi:10.1186/bcr2887

Cite this article as: Cardiff RD, et al: Three interrelated themes in current breast cancer research: gene addiction, phenotypic plasticity, and cancer stem cells. Breast Cancer Research 2011, 13:216. 